\title{
Children as inventors: Orchestrating an informal pedagogic scenario with digital resources
}

\begin{abstract}
A pedagogic scenario is described for providing primary school children with an understanding of the processes of invention, while cultivating a sense of identity as 'inventor'. This scenario is positioned at the boundary of in-class and out-of-class experience. Our central aim was to illustrate how digital resources might function to orchestrate the experience of invention. To this end, we distinguish the role of such resources in terms of their contributions to the following elements of invention: inspiration, expression, reflection, and production. This framework for addressing invention as a creative activity allows it to be experienced as authentic, collaborative, and free of biases associated with gender or curricular disciplines. Examples of the inventions conceived in this workshop are presented and a taxonomy for describing them is offered.
\end{abstract}

\section{Introduction}

There is some uneasiness about how notions of 'invention' and 'inventor' should be defined: what practices do these terms imply? Huber (1998) has reflected on this at some length and encourages adopting the particular formulation associated with patent office definitions: namely, "new, useful and unobvious". This offers a good starting point for the perspectives developed in the present report. Here we describe workshops in which young children are led towards addressing problems that invite solutions with this flavour (i.e., inventions) and solutions that are of their own making (i.e., the work of inventors). The creative energy in these workshops was released and coordinated by a variety of digital resources and it is the potential of such technology that we wish to address in the present report. However, first of all, it is important to note that there are good reasons for constructing an inventing opportunity of this kind. One reason is because it is common for popular political debate to highlight inventiveness as an important ingredient of economic progress (as well as creative expression). Yet, despite this sense of importance in wider society, many commentators have noted that invention is not a form of activity in the foreground of the school curriculum (e.g., McCormick, 2004; Plucker and Gorman, 1999).

There are certainly authors who have made the case that invention should be a more prominent part of the curriculum (e.g., Gunnarsdottir, 2001; Lewis, 2009). Where it is to be found most explicitly acknowledged and actively cultivated is in the context of 'Design and Technology' teaching, where the value of encouraging invention is often acknowledged (Gorman et al, 1995; Plucker, 2001; Westerberg, 1996). Yet Design and Technology is a subject that is not encountered by many 
students and generally not at all part of early years education - even though it may be that the early years are where an 'inventive attitude' might be most usefully established. However, if there is to be a pedagogy of invention in this sector of education, existing literature offers some pointers as to the form that it might most usefully take.

One principle that has been widely advocated will be developed in the present report: namely that of locating inventing and inventors in the lived experience of the child's own world. Hill (1998) has argued for the importance of finding problems in the "real life contexts" of student inventors. In her study, she constructs an invitation to invent in the context of ongoing, if background, projects that are active in the school environment. These would be projects that are suggested and established by students themselves as naturally engaging (e.g., putting on a play). Another principle that influences the present research is a wariness of pathways for design initiatives that may be too rigidly enforced. Authors who argue for authenticity may also urge freedom to explore the possibilities of invention in an iterative manner, rather than having the student inventors constrained by formulaic design pathways (Mawson, 2003).

There are other aspects of the invention process that are important to acknowledge and address. One of them is the popular conception of invention as somehow in the realm of "mysterious genius" (Gorman and Carlson, 1990). This phrase hints at a number of prejudices: these are attitudes and expectations that we have been concerned to address. One prejudice is the idea that such "genius" is typically exercised mainly in the subject domains of science, another is that the geniuses themselves are typically male. For instance, at the time of writing, a search in Google images on the keyword "inventor" delivers a large number of images that suggest particular expectations about what this word refers to: namely, science, engineering, and being male. So of the first 20 human figures shown in this search, 15 are male. And of the female, 2 are presented as passive consumers or witnesses of invention rather than active agents. Thus educational interventions in this area would do well to address a number of such questionable assumptions around the practice of invention. Its gender-specificity and subject-specificity are certainly two such assumptions. Another is the manner in which the discourse of invention tends to stress solitary reflection at the expense of social construction (Calabrese-Barton, 1998).

Certainly inspiration can come from private and independent thought. A popular example is J.K. Rowling's invention of the Harry Potter stories while sitting alone and staring passively out of a train window $^{1}$. However, many commentators have shown that projects with a strong component of student invention work well when they are organised in more social configurations (e.g., Fields,

\footnotetext{
${ }^{1}$ http://www.inspiredminds.de/detail.php?id=5
} 
1987; Druin and Fast, 2002). Yet with the kind of open-ended and exploratory problem solving that is typical of student invention exercises, it is likely that progress and success will depend on a degree of social coordination: perhaps something only achievable through the presence of experienced adults. Indeed, the study by McCormick et al (1994) illustrates the importance of teachers in effecting that coordination. While Murphy and Hennessy (2001) illustrate how significant the teacher's presence is in managing the particular demands of small group collaboration around any task centred on invention.

This management challenge can apply to a wide variety of those classroom activities that have some degree of openness or flexibility. Kennewell has invoked classroom digital technology as a source of support for such activities and referred to how it may thereby "orchestrate" those activities (Kennewell, 2004). It might be expected that technology normally enters into an invention project for the purposes of engineering a final product - a toll for construction. However, here we are keen to stress the role of technology as a resource for social orchestration: an important resource where collaborative work is central to what is being done (Dillenbourg et al, 2012). The capability of this technology for capturing, annotating, representing and sharing ideas is highly promising in a situation where knowledge development is fluid and negotiable. So, it will be important to have tools that record transitory opportunities for reflection, that represent evolving ideas for discussion, and that allow active manipulation of the current status quo in a project - if its progress is to be iteratively managed.

In the present report, we wish to explore the value of technology in supporting the 'front end' of the typical invention trajectory. That is to say, managing the point at which an initial inspiration for the task of invention is established. Arguably, this defines a challenge - finding a point of motivation that is relatively neglected in classroom design exercises. Many case studies of inventive activity in the classroom handle the starting point with a problem that is pre-defined - such as creating a story telling environment in software (Druin and Fast, 2002), or imaginatively resourcing the production of a school play (Hill, 1998). In the spirit of locating invention in fully authentic circumstances, we wish to explore how technology can help young people find 'problems' in their immediate personal, recreational, and school environment : circumstances that are ripe for inventive solutions. As Howard-Jones (2002) emphasises, creativity is about generating ideas as well as analysing them. And as Pickering (1995) points out, many inventions in science have depended upon progress in the detection of problems. To this end, we aimed here to recruit technologies that allow the capture and sharing of inspirational problems. 
Yet analysis certainly is required, in addition to generative observation. For instance, Druin and Fast (2002) highlight how the keeping of personal journals can assist the reflective process. Therefore, we wish to explore how digital technology can interweave the generative, the reflective, and the discursive towards the problems that have been identified as ripe for solution.

In the brief review above, we have identified a number of themes that suggest the design of a possible pedagogic scenario: one that might be innovative as a basis for giving young people a rich experience of invention. First, we wish to address our interventions towards students who are within early education. This is based on a belief that an inventive mindset is best seeded at an early point in educational experience. Second, we wish to stress the challenge of finding inspiration: creating an attitude of scrutinising the world to imagine it could be otherwise and, thereby, finding 'problems' that become the stimulus for invention. This implies an emphasis on principled exploration and reflective annotation. Third, we wish the process of invention to be inclusive and socially-mediated. This implies we define our activities in a way that is equally appealing to male and female students and that we organise the experience to optimise collaborative understanding among peers and productive scaffolding of activity with adults. Fourth, we recognise that the exploratory nature of such an exercise means that it is best located outside of the official curriculum but, ideally, inside of the school. This suggests a workshop structure that is fitted into out-of-class time.

Finally, in view of the rich and open nature of these circumstances for inventing, we are anxious to frame what happens within some structure of effective representational and exploratory support. We believe that the current state of classroom technology offers solutions to this particular challenge. Therefore, the focus of the present report is upon the tools that can be important in this orchestrating role and their contribution to defining the terms of an informal pedagogic scenario for inventing. In what follows, we describe our experiences of refining such a scenario as it took place in a lunch club offered to successive cohorts of elementary school children over a three year period.

\section{Method}

Our general approach to method was to adopt the status of participant researchers. That is, both researchers oversaw the running of the invention workshop sessions, as well as capturing the events and artefacts that arose in order to systematise them for purposes of this report.

\section{Context}

The inventors' workshops took place in the computer room of a primary (or elementary) school serving a mixed catchment area. They occurred in lunch breaks on a designated day of most weeks 
during a single term. Activities were also encouraged outside of school and some walks around the school premises also took place - as described below. Three different cohorts of students took part over three successive school years.

\section{Participants}

The workshops were led and coordinated by the two authors of this report. Students from years 5 and 6 of primary (elementary) schooling (aged between 9 and 11) were invited to volunteer for this activity following an in-class explanation of what was involved. Across the three years, a total of 23 girls and 21 boys sustained sufficient engagement to produce an invention book (as described below). Our report is based on records arising around and within their activities. Wherever possible students worked in pairs, although they were each encouraged to produce their own invention book. However, the pairing meant that some invention reports were repeated in different books.

\section{Procedures}

The structure of each session took the form of: (1) an introductory conversation led by the authors that involved: (i) an update on general and individual progress in the previous session and, where appropriate, for the period in between, (ii) critical exploration of nominated and emerging inventions, and (iii) a suggested plan for that day; (2) the core activity for that day, in which students would work either individually, in friendship pairs, or in small groups; (3) a plenary session in which progress was reviewed and discussed. A significant percentage of the core activities in (2) would be conducted at networked computers with the authors (and sometimes postgraduate helpers) engaging from time to time with the students. On at least one occasion in each of the year groups there was a problem-seeking walk around the school. In addition, students were encouraged to capture and annotate 'problems' in their own environment that invited solution by invention. During weeks that students elected to gather problems out of school they were loaned a small combined camera and voice recorder and encouraged to photograph their found 'problems' and make voice notes describing them. The record of their ideas were developed and displayed in an online e-book. The workshops also had a website that was maintained by the authors but visible to the students and their families.

Our broad strategy was as follows: to stimulate the inventive process, to encourage its documentation and development and, finally, to make efforts to realise inventions in material form. We expected to evolve the ingredients and tactics of our potential pedagogic scenario in the light of evolving experience and workshop practice was inevitably developed towards a stable structure in an iterative manner - a stability that we believe was in place when completing the second of the 
three annual cohorts. The two main dimensions of development conceived in these terms was, first, to concentrate effort on finding problems that afforded inventive thinking and, second, to reduce effort on the production of material versions of any inventions that were conceived. A key component of our strategy was to encourage and resource a critical approach to invention. So, when students had found a problem and proposed an invention-as-solution, they were encouraged (in collaboration or in plenary discussion) to find problems with their solution and to launch a second "improvement" stage. The outputs of these various deliberations (including relevant sketches) were to be presented in the pages of their individual e-books. These in turn were made visible to others.

\section{Analysis and Findings}

Because we wish to dwell upon the technological support of a pedagogic scenario, the prime intention in reporting findings is to present a reflective, narrative account of the manner in which workshops of this kind might be effectively orchestrated. However we may still give some indication of the nature of the creative activity that they stimulated. To these ends, we draw upon the following records of the project.

(1) 19 recordings of introductions and plenary sessions that were captured at representative points in the trajectory of each workshop series.

(2) Our own field and planning notes of sessions.

(3) 44 individual e-books, each describing "my inventions".

(4) 19 spoken diary records from voice recorded field work

(5) 42 unique photographs of spaces or artefacts that were 'problematic'

(6) 46 drawings of inventions

Our main analytic concern here is to dwell upon the way in which a variety of digital resources may be recruited to orchestrate workshops of this kind and to identify the nature of the orchestration that seemed to be required. This will involve some acknowledgement of the nature of the students' inventions and, accordingly, a categorisation scheme is proposed later in this section. We have organised the orchestrating process under four headings: inspiration (finding a problem that invites an invention), expression (making the problem and the solution visible), reflection (evaluating and improving an invention), and production (making the invention visible).

Inspiration. Although the concepts of invention and inventor were quite accessible to these students and although they were strongly engaged by the idea of this workshop, it was clear from an early point that students would not arrive with well-developed ideas of their own. Moreover, early conversations were dominated by an "everything's been invented already" mindset. We therefore 
evolved a number of strategies for motivating invention. These necessitated encouraging an attitude of 'problem-seeking', or interrogating the environment for places, things or practices that were somehow or sometimes troublesome. However, it was important that such problematic circumstances should be firmly captured: they would thereby be available for scrutiny and discussion within peer collaboration and within plenary discussions. Accordingly, students were loaned a digital camera and voice recorder. They were then invited to interrogate their environments with these technologies as resources for recording what they found there that was troublesome and inviting adjustment or change. These recorders were first used on walks around the school environment, each with an adult who encouraged development of the various tentative observations. Students were then invited to take their recorders home and make a similar audit of their domestic environment. For the final cohort, there was contact with a North American school by email: this furnished some exchange of local problems with an invite for each side to suggest solutions for the other.

Expression: one of the reasons for seeking pictorial records of local 'problems' was to resource the subsequent negotiation of their understanding: in particular, resource collaborative discussion of inventive approaches towards them. Thus the digital image became the expressive representation of a problem that was readily shared with others in the group. For instance, during plenary sessions a slideshow was used to bring these ideas into a space of conversation. While, during peer collaborations at individual computers, the digital images could be viewed again. The same capture device also allowed an audible recording of an individual's thoughts at the time that an image was captured or reflections at other times when inventive possibilities occurred to them.

Reflection: This was encouraged by issuing each student with a private "inventor's notebook" where they were encouraged to keep diary-style thoughts about possible inventions and thereby construct a personal journal (following Doppelt, 2007; Druin and Fast, 2002). As indicated above, the images and recordings were part of what resourced private and social reflection about emerging ideas. That reflection might occur in plenary discussion but the e-book application allowed the development of an invention to be visible for commentary in a more narrative form. Thus students were encouraged not only to place their photographs, drawings, and text description in this digital book, they were encouraged to do so in a narrative manner. In particular, a standard framework was encouraged whereby the book would first reveal a problem, then an invention was described to address it, then this was critiqued as a source of its own problems and, finally, a revision of the original design was proposed. The book provided a record of this process and one that could enter into discussions with peers and with the scaffolding adults. While much reflection was mediated within such traditional 
social exchange, an additional digital resource was developed to stimulate reflection further. On the workshop website, students were encouraged to submit their designs for scrutiny by an unknown "wizard". This idea was borrowed from the same figure performing a similar challenging role in Cole's $5^{\text {th }}$ Dimension - a similar after-school workshop (Cole and The Distributed Literacy Consortium, 2006). The wizard provided feedback and, sometimes, design challenges that encouraged further thought about how an invention might be improved.

Production: Our intention had been to recruit traditional classroom construction material to bring to life some of the inventions. However, it quickly became apparent that this was over-ambitious. While the students indicated that they were realistic in their expectations about what could be actually built, but we nevertheless felt that it was important to acknowledge their achievements at some level in relation to production. We therefore authored simple flash animations that illustrated the look and action of some popular inventions. This form of digital artefact is available to be examined at this web address: http://deveurope.com/inventors/. It represented one way in which a digital design tool and digital publication site could support the natural endpoint of an invention. Another digital solution to the challenge of realising production was found in the e-books. As indicated above, the e-books were an important vehicle for organising reflection but they also could be regarded as a destination for the final representation of the inventor's effort. On this conception, the "product" could be regarded as the visible enactment of an invention achievement - considered as a process. That is, a narrative of conception, commentary, improvement, and final design. By making both printed and digital versions of the e-book available to friends and family, it was possible to arrange for the creative effort to be rewarded by dissemination.

The process of orchestration described above brought about an engaged and creative community of invention. It was very rare for any student to withdraw from these workshop sessions and individual session attendance remained consistently high. More important, the animated discussions and careful research generated much creative thinking. It is therefore appropriate to comment on the nature of the inventions that can be generated by a pedagogic scenario of the kind outlined here.

In the Introduction to this paper, we identified 'inspiration' as a central concern of the workshop enterprise. Special attention was invested in encouraging students to interrogate their environments for 'problems'. These would become possible stimuli for the inventor: the potential source for some creative thinking. Much of our discussions were concerned with identifying, articulating, and refining these problem spaces. Given this investment, it is interesting to consider what form such found problems took. Table 1 offers a taxonomy of the 71 distinct problems-for-invention that were put forward (some suggestions were offered by more than one student, then only one example is 
coded in this table). Problems seemed to originate from three sources. They might suggest the struggle of an individual against some sort of 'adversity'. Or they resided in the constrained usability of some artefact or other. Or they were a recurring problem in some more coarse grained feature of the world - some kind of poor design in the material environment.

Interestingly, over half of the problems found were 'personal': that is, they had their origin in the inventor-students' own experience, their own activities and practices. Other problems were evenly distributed between general design shortcomings perceived within individual artefacts or the wider environment. It is notable that only one item was offered that referred to problems experienced by a particular person other than the self (a person who is blind). Of the problems that had their focus in personal activity, we distinguish three sorts. First, those that were described in terms of an irritation: in particular, possessions getting lost, discomforts or illnesses, or an unappreciated sibling. Second, those that refer to the unwelcome demands of effort that are made by some tasks or responsibilities: such as household chores or responsibilities. Third, there were inventions that were not sourced from particular problems - other than dissatisfaction with the inevitable limits of human capacities. These occurred as inventions of a sort that are classically associated with childhood imagination: such as voice activated devices, superfast and versatile vehicles and other James Bond style gadgets.

--- Insert Table 1 about here ---

The second broad class of problems concerned the usability of particular artefacts. Here the challenges seemed to be matters of "repair": that is, rectifying inevitable processes of ware or malfunction. While other challenges seemed to be opportunities for "refining" the artefact: that is, elaborating its design to increase its potential utility. The third class we associated with problems in the wider environment rather than particular artefacts. These might be a matter of coping with an environment that was "inhospitable" (spaces that were dirty or neglected, the impact of bad weather, etc.). Or they might be a matter of an environment that was "obstructive" to the fluency of some activity or other (providing insufficient space, or dangerous surfaces, etc.).

Student representation of their inventions are illustrated in Figure 1. These were produced sometimes in the inventor's notebook, sometimes in a computer painting package and sometimes in both. All of these examples illustrate the inspiration of a strong problem. Respectively they are: not understanding the baby sibling, a bike that gets stuck in muddy ground, the chore of cleaning, and an excess of litter in the school area. 
They also illustrate the commonplace strategy of placing faith in unspecified 'automation'. So, in (1) the process solution is merely a matter of putting a 'box' between the problem and the user: this device then takes care of translation mechanics in an automated fashion. In (3) the functionality of the 'machine' is made more explicit - but it is simply realised as the routine practices of human cleaning appropriated by the robot device. In other cases, isolated features of existing technologies are borrowed piecemeal - as in (2) where the hovering principle is used to lift the rear suspension of a bike and protect it from getting bogged down in rough ground. The images also illustrate how representations might be made by hand for scanning from the notebook $(3,4)$ as well as made directly in a computer paint package $(1,2)$. In both cases they became an important part of the invention narrative gathered in the online book for sharing.

\section{Discussion}

We have described a pedagogic scenario that can effectively stimulate the notion of 'invention' and cultivate the identity of 'inventors' among young learners. A particular aim here has been to note how familiar resources of digital technology can be mobilised to help achieve the demanding task of 'orchestrating' such an experience. Although the present scenario is termed 'pedagogic', it has purposely been achieved in the boundary space between formal and informal learning.

Consequently, the pedagogy is one that can be shaped to fit more firmly either side of that boundary - as circumstances allow. In this discussion, we note how technology has effectively mediated the various challenges that the literature has identified for those who wish to develop creative activities through the vehicle of invention.

It was noted at the start of this report that there is a challenge of inspiration or motivation. How to get the inventive imagination triggered is a practical problem that has been neglected. A central aim here was to seed such engagement by raising expectations that something could be invented - that not everything that might be discovered or designed had already been achieved. This may be expressed by saying that the inventor must have an attitude that regards the design of the world as contingent: things could be otherwise. This, in turn, required a strategy whereby the student inventor must interrogate their environment. This has been achieved here by recruiting technologies (camera and voice recorder) that invite such active scrutiny of the local world. 
Moreover, effective engagement may have depended on the fact that it was the local world (the school and the home) that was interrogated in this way (cf. Hill, 1998).

Such recording technology does serve to encourage engagement (the school walks and the home audit were regarded as fun) but it also serves to support another important theme identified earlier as central to the invention experience - namely that it should have a social quality, that it should be discussed, debated and negotiated (Calabrese-Barton, 1998). The images and narrations that were captured in this way became stimuli for that social process. It may be straightforward to create the conditions for inspired invention, however this achievement must be built upon. This depends on creating the conditions for reflection and debate around the problems that have been captured and defined. Indeed a significant motive for organising activities of this kind at all resides in the opportunity to stimulate such thinking. So, a major focus of many established invention programs is to develop students' ability to reflect on their problem-solving (e.g., Gorman et al., 1995; Westberg, 1998). The images captured during problem-finding were absorbed into the plenary and introductory sessions by the researchers harvesting this material into a shared slideshow around which discussion was organised. Similarly, these images could be discussed by pairs or small groups as they worked together at individual computers

The ability to focus research and problem definition at this local level also served other ends that were identified as important in our Introduction. The targets for invention here were not cast so strongly in the familiar domains of science, and the identity of 'inventor' seemed to be more legitimately appropriated by all - rather than conforming to the male stereotype.

If inspiration is the starting point for the present form of activity, then production is where it should converge. There is evidently a risk of losing the student-inventor's enthusiasm if their efforts do not lead to some sort of tangible product. It was therefore important in the present scenario to have a destination of this kind defined. While animation technology has some modest potential for rendering an invented idea active, we relied here on the attraction of an invention narrative (as represented in the e-book) as the product motive. These books turned out to be appealing, not least because they were readily shared with family and friends and so extended the visibility and admiration for the creative effort that the students had invested.

We have not chosen to dwell on the creative thinking processes that were revealed in the course of this activity. One aspect of the exercise that suffered was the invitation to improve inventions. Only $21 \%$ of the reported inventions included reflections and solutions that responded to the prompt to think of drawbacks and improvements on the originally reported idea. However, this was a 
restriction of time: for it was not such a difficult issue to manage at the level of the plenary discussion, where considerations of improvement were often animated. In fact the recordings indicate that students were very active in finding flaws (and also potential) in the reported inventions of their peers. However, these ideas were less readily migrated into the e-book accounts of individual students.

The e-book was certainly an important factor in sustaining the engagement of students with this pedagogic scenario. More generally, centring the activity on a computer room and organising the collaboration at individual workstations seemed an appealing aspect of how the workshop was experienced. The invitation to invent may be one of those opportunities that is appealing in principle but often difficult to realise in practice. Yet, here, we were impressed by the creative achievements, but also by the engagement of these young inventors. They sustained regular attendance over the course of a school term and they furnished a large number of ideas that were enthusiastically discussed at a group level and pursued with care at the level of individual creative effort. The conversations that we witnessed were characterised by breadth of imagination and depth of reflection, suggesting that this is a worthwhile activity to cultivate - even if only in an outof-lesson context. Moreover, the ready availablity of the technologies we have highlighted in this report can act as an important resource for creating inspiration, coherence and engaging output.

\section{References}

Cole, M. \& The Distributed Literacy Consortium. (2006) The Fifth Dimension: An after-school program built on diversity. New York: Russell Sage Foundation.

Calabrese-Barton, A. (1998) Examining the Social and Scientific roles of invention in science. Research in Science Education, vol. 28, No. 1, pp.133-151.

Dillenbourg, P., Dimitriadis, Y., Nussbaum, M., Roschelle, J., Looi, C-K., Asensio, J., Balaam, M., Chan, T-W., Diaz, A., Evans, M., Fischer, F., Hoppe, U., Kollar, I., Perrotta, C., Prieto, C., Sharples, M., Song, Y., Tchounikine, P. (2012) Design for Classroom Orchestration, Computers \& Education, Available: ISSN 0360-1315, 10.1016/j.compedu.2012.10.026 [13 Dec 2012].

Doppelt, Y. (2009) Assessing creative thinking in design-based learning, International Journal of Technology and Design Education. vol. 19, No. 1, pp.55-65. 
Druin, A. \& Fast, C. (2002) : The Child as Learner, Critic, Inventor, and Technology Design Partner: An Analysis of Three Years of Swedish Student Journals. International Journal of Technology and Design Education vol. 12, No. 3, pp.189-213.

Fields, S. (1987), Introducing Science Research to Elementary School Children, Science $\&$ Children 24, No. $1,18-20$.

Gorman, M., \& Carlson, W. B. (1990) Interpreting invention as a cognitive process: The case of Alexander Graham Bell, Thomas Edison, and the Telephone. Science, Technology and Human Values, vol. 15, No. 2, pp.131-154.

Gorman, M. E., Richards, L. G., Scherer, W. T., \& Kagiwada, J. K. (1995) Teaching invention and design: Multi-disciplinary learning modules. Journal of Engineering Education, vol. 84, No. 2, pp.175-186.

Gunnarsdottir, R. (2001) Innovation Education: Defining the Phenomenon. Unpublished Ph.D thesis, The University of Leeds, Leeds, United Kingdon.

Hill, A. M. (1998), Problem Solving in Real-Life Contexts: An Alternative for Design in Technology Education, International J ournal of Technology and Design Education vol. 8, No. 3, pp.203-220.

Howard-Jones, P. A. (2002) A dual-state model of creative cognition for supporting strategies that foster creativity in the classroom. International Journal of Technology and Design Education, 12, No. 3, pp.215-226.

Huber, J. C. (1998), Invention and Inventivity as a Special Kind of Creativity, with Implications for General Creativity. The Journal of Creative Behavior, vol. 32, No. 1, pp.58-72.

Kennewell, S. (2001) Using affordances and constraints to evaluate the use of ICT in teaching and learning. Journal of IT and Teacher Education, vol. 10, No. 1, pp.101-116.

Lewis, T. (2009) Creativity in technology education: Providing children with glimpses of their inventive potential. International Journal of Technology and Design Education, vol. 19 , No. 3 , pp.255-268.

Mawson, B. (2003) Beyond The Design Process': An Alternative Pedagogy for Technology Education. International Journal of Technology and Design Education vol. 13, No. 1, pp.117-128. 
McCormick, R. (2004) Issues of learning and knowledge in technology education. International Journal of technology and Design Education, vol. 14, 21-44.

McCormick, R., Murphy, P., \& Hennessy, S. (1994) Problem solving processes in technology education: A pilot study. International Journal of Technology and Design, vol. 4, No. 1, pp.5-34.

Murphy, P. \& Hennessy, S. (2001), Realising the Potential - and Lost Opportunities - for Peer Collaboration in a D\&T Setting, International Journal of Design and Technology Education, vol. 11, No. 3, pp.203-237.

Pickering, A. (1995) The mangle of practice: Time, agency, \& science. Chicago, IL: University of Chicago Press.

Plucker, J. A. (2001) What's in a name? Young adolescents' implicit conceptions of invention. Science Education, vol. 86, No. 2 pp.146-160.

Plucker, J. A., \& Gorman, M. E. (1999) Invention is in the mind of the adolescent: Effects of a summer course one year later. Creativity Research Journal, vol. 12, No. 2, pp.141-150.

WESTBERG, K. L. (1996), The Effects of Teaching Students How to Invent. The Journal of Creative Behavior, vol. 30, No. 4, pp.249-267.

Westberg, K. L. (1998) Stimulating children's creative thinking with the invention process. Parenting for High Potential, vol. 25, September, pp.18-20. 


\section{Tables}

\begin{tabular}{|l|r|l|}
\hline \multicolumn{1}{|c|}{ Problem stimulus } & $\%$ & \\
\hline Personal stress (irritation) & 25 & $\begin{array}{l}\text { An inconvenience or discomfort centred on the self. } \\
\text { Examples: too cold in bed; loosing glasses; hayfever; sibling } \\
\text { shares room but gets up earlier }\end{array}$ \\
\hline Personal stress (effort) & 11 & $\begin{array}{l}\text { Some personal task that could take less effort than it does now. } \\
\text { Examples: mowing the grass; getting up in morning; doing maths }\end{array}$ \\
\hline Personal empowerment & 20 & $\begin{array}{l}\text { Exotic prosthesis for amplifying existing personal powers. } \\
\text { Examples: Moving faster; doing make-over; temperature control }\end{array}$ \\
\hline Others' stress & 1 & $\begin{array}{l}\text { An inconvenience, discomfort or demand centred on others. } \\
\text { Example: helping a person who is blind navigate }\end{array}$ \\
\hline Artefact: repair & 11 & $\begin{array}{l}\text { Usability problem with material artefact design. } \\
\text { Example: light bulbs get dirty; broken taps in bathroom }\end{array}$ \\
\hline Artefact: refinement & 11 & $\begin{array}{l}\text { Creatively extending the usability of an artefact. } \\
\text { Example: the bath overflows; bird feeder dominated by big birds }\end{array}$ \\
\hline Environment: inhospitable & 14 & $\begin{array}{l}\text { Some feature of the environment is source of irritation. } \\
\text { Examples: dirt; litter; rain stops playing }\end{array}$ \\
\hline Environment: obstructive & 6 & $\begin{array}{l}\text { Some feature of the environment obstructs fluent action. } \\
\text { Examples: lack of space; surfaces that can injure }\end{array}$ \\
\hline
\end{tabular}

Table 1: A taxonomy of problems for which inventive solutions were sought 


\section{Figures}

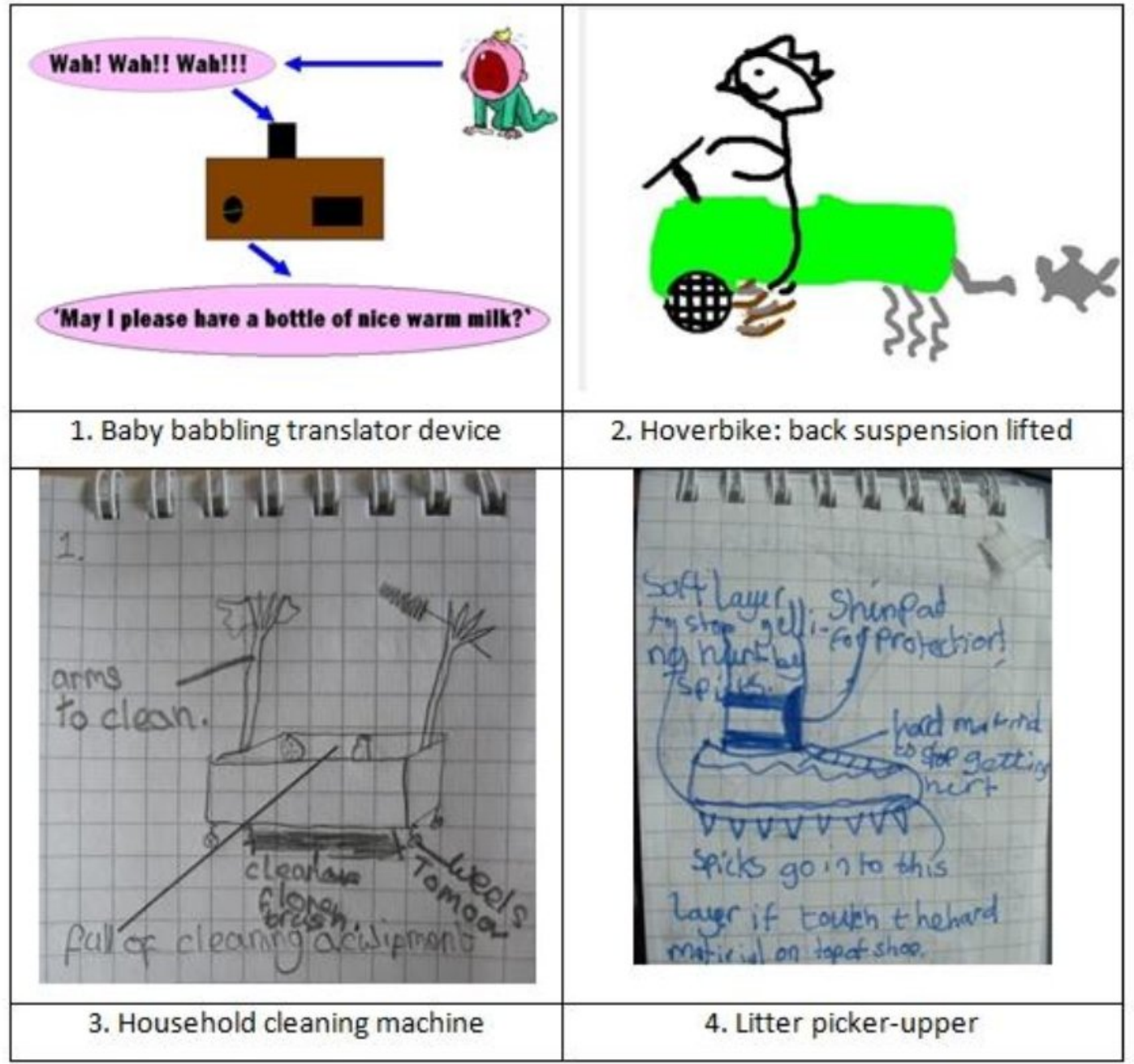

Figure 1: four examples of invention representations (rendered here in grey-scale) 


\section{Keywords}

Inventors

Invention

Pedagogic scenario

Digital resources

Primary school

Informal education 